\title{
İnflamatuar Bağırsak Hastalıkları Olan Bireylerde İlaç Uyumu ve Yaşam Kalitesi
}

\author{
Drug Compliance and Quality of Life in Patients with Inflammatory Bowel Disease
}

\section{Nazı ÖZTÜRK* iD, Yasemin YILDIRIM** iD}

\section{ÖZET}

Inflamatuar bağırsak hastalıkları genetik, çevresel, immün sistem gibi birçok faktörün sorumlu tutulduğu nedeni tam olarak bilinmeyen gastrointestinal sistemin kronik inflamasyonudur. Dünya genelinde inflamatuar bağırsak hastalıklarının insidans ve prevelansının gün geçtikçe artması, kronik olması, ömür boyu ilaç kullanımını gerektirmesi, rölapsların önlenmesi ve remisyonun sağlanabilmesi için ilaç uyumunun üst düzeyde olması önemlidir. Bu derlemenin amacı inflamatuar bağırsak hastalıkları olan bireylerde ilaç uyumu ve yaşam kalitesi arasındaki ilişkiyi incelemektir. Sağlık profesyoneli olan hemşireler ekip işbirliği ile hastaların ilaç uyumunun arttırılmasına yardımcı olarak yaşam kalitesinin yükseltilmesine katkıda bulunabilir.

Anahtar Kelimeler: İnflamatuar bağırsak hastalıkları, İlaç uyumu, Yaşam kalitesi

\begin{abstract}
Inflammatory bowel diseases is a chronic inflammation of the gastrointestinal tract, which is not known exactly why many factors such as genetics, environmental and immune system are held responsible. It is important to have a high level of drug compliance in order to increase the incidence and prevalence of inflammatory bowel diseases worldwide day by day, to be chronic and to require life-long drug use, to prevent relapses and to ensure remission. The aim of this review is to examine the relationship between drug compliance and quality of life in individuals with inflammatory bowel diseases. Nurses, who are health professionals, can help improve the quality of life of the patients by helping to increase drug compliance of the patients with team collaboration.
\end{abstract}

Keywords: Inflammatory bowel diseases, Drug compliance, Quality of life

\footnotetext{
* Araş. Gör., Akdeniz Üniversitesi Hemşirelik Fakültesi, İç Hastalıkları Hemşireliği Anabilim Dalı

${ }^{* * *}$ Prof. Dr., Ege Üniversitesi Hemşirelik Fakültesi, İç Hastalıkları Hemşireliği Anabilim Dalı
}

Sorumlu Yazar / Corresponding Author: Nazlı ÖZTÜRK, ozturknaz@outlook.com 


\section{GíRIŞ}

İnflamatuar bağırsak hastalıkları (IBH), Crohn $(\mathrm{CH})$ ve ülseratif kolit (ÜK) hastalığını içeren gastrointestinal sistemin kronik inflamasyonudur (Mahalli \& Alharthi, 2017). Dünya genelinde yaklaşık 11.2 milyon insanı etkileyen İBH'nin Avrupa ve Kuzey Amerika'da sıklığının daha fazla olduğu bildirilmiştir (Malinowski, Wiciński, Sokołowska, Hill \& Szambelan, 2020). İnflamatuar bağırsak hastalıkları 10-35 yaş grubunda daha sık görülmekte olup kadınlardaki insidansı erkeklere oranla daha fazladır (Malinowski et al., 2020; Mahalli \& Alharthi, 2017). Crohn'lu hastaların \%50'sinden fazlasında zamanla cerrahi müdahale gerektiren komplikasyonlar gelişmektedir ve ülseratif kolitli hastalarda hastalığın gidişatına bağlı olarak \%20-30 oranında kolostomi açılmaktadır (Fiorino et al., 2019).

Ülseratif kolit, kolon ve rektumun mukoza ve submokoza tabakalarını tutarken; Crohn hastalığında hastaların yaklaşık \%20'sinde izole kolon tutulumu, \%30'unda ince bağırsak ile sınırlı \%50'sinde hem ileum ve hem kolon tutulumu görülmektedir (Kózka, Skowron \& Bodys-Cupak, 2019; Khanna et al., 2016). Ülseratif kolitin yıllık insidansı ortalama 10/100000 iken Crohn hastalığının prevalans oranlarına bakıldığında Avrupa 100 000'de 322, Kanada 100 000'de 319 ve ABD'de 100 000'de 214 ile en yüksektir (Hwang \& Yu, 2019; Torres et al., 2017). Ülseratif kolitte hastalık kendini eritem ve ülserasyon ile göstermektedir. Özellikle hastalığın alevlenme dönemlerinde rektal kanama, kanlı, diyare, ateş ve hastanın günlük yaşam aktivitelerini önemli ölçüde etkileyen ağrı önemli belirti ve bulgulardır (Kózka et al., 2019; Hwang \& Yu, 2019). Crohn hastalığına ise abdominal ağrı, kronik diyare, yorgunluk, kilo kaybı önde gelen belirti ve bulgulardır (Seyedian, Nokhostin \& Malamir, 2019).Ülseratif kolitin tedavisinde; siklosporin, Anti TNF ve vedolizumab kullanılmaktadır (Davis et al., 2018; Stansfield, 2016). Crohn hastalığının tıbbi yönetiminde ise amaç; klinik ve endoskopik remisyonu sürdürüp nüks, bağırsak perforasyonu ve cerrahi müdahale ihtiyacından kaçınmaktır (Pudipeddi et al., 2019). Geleneksel tedavilere yetersiz yanıt alınan hastalarda biyolojik ajanlar reçetelenmektedir (Campos, Portela, Sousa \& Sofia, 2016; Pudipeddi et al., 2019).

Alevlenme ve remisyon dönemleriyle seyreden bu iki hastalık grubu hastaları biyopsikososyal yönden önemli ölçüde etkileyerek sakatlıklara yol açabilmekte ve yaşam kalitesini düşürmektedir (Fiorino et al., 2019). Tüm kronik hastalıklarda olduğu gibi inflamatuar bağırsak hastalığına sahip bireylerde uzun süreli ilaç kullanımı gerekmektedir ve hastaların ilaç uyumunun yüksek olması ile ancak yaşam kalitesinin arttırılması mümkün olmaktadır. Bu derlemenin amacı; inflamatuar bağırsak hastalığı olan bireylerde ilaç uyumu ve yaşam kalitesini incelemektir.

\section{İnflamatuar Bağırsak Hastalıklarında İlaç Uyumu ve Yaşam Kalitesi}

Uyum; bir bireyin davranışlarının, sağlık profesyonelleri tarafından önerilen ilaç alma, diyet, yaşam tarzı değişikliği gibi parametrelerle ne ölçüde örtüştügüdür (Chang \& Lee, 2015). İlaç uyumu 
ise; hastaların kendilerine reçete edilen ilaçları (günde bir ya da günde iki, aç, tok, düzenli, belli bir dozda vb.) ne ölçüde aldıkları olarak tanımlanmaktadır (Chang \& Lee, 2015; Hromadkova, Soukup, Cermakova \& Vlcek, 2012). İlaç uyumu, kronik hastalıklarda tedavi etkinliğinin önemli bir bileşenidir (Hromadkova et al., 2012). Ancak hastaların genellikle ilaç tedavisine yeterince uyum göstermedikleri belirtilmektedir (Trindade, Ehrlich, Kornbluth \& Ullman, 2010). Dünya Sağlık Örgütü verilerine göre kronik hastalığa sahip bireylerin yaklaşık \%50'si ilaç tedavisine uyum göstermektedir (Hromadkova et al., 2012; Trindade, Ehrlich, Kornbluth \& Ullman, 2010).

İlaç uyumunun düşük olmasının nedenleri arasında; reçete edilen ilaçların kullanımının yanlış anlaşılması, ilaç tedavisinde sık değişiklikler olması, birden fazla doktorun aynı ilacı reçete etmesi, ilacın hastalığı iyileştireceğine inanılmaması, okuma-yazma bilinmemesi, unutkanlık, hastalık tanısının reddi veya yeterince önemsenmemesi, depresyon, semptomların azalması ya da kaybolması, ilaç bağımlılı̆̆ı korkusu, ilaca erişimi veya ilaç kullanımını sınırlayan fiziksel zorlukların varlığı (tabletleri yutma problemi, ilaç kaplarını açmada zorluk çekmek, küçük tabletleri tutmada zorluk çekmek vb.), sosyal veya aile destek sistemlerinin sınırlı olması, madde bağımlılığı, evde ilaç kullanımını yönlendirmede yardımcı olabilecek kimsenin olmaması yer almaktadır (Dewulf, Monteiro, Passos, Vieira \& Troncon, 2007; Vlasnik, Aliotta \& DeLor, 2005).

Hastalarda ilaç uyumunu değerlendirmenin standart bir yöntemi olmamakla birlikte direkt ve indirekt yöntemler kullanılarak hastanın ilaç uyumu değerlendirilebilmektedir (Manmohan et al., 2012; Osterberg \& Blaschke, 2005). Hap sayımı, ilaç doldurma kayıtları, hastanın geri bildirimleri, yarı yapılandırılmış görüşmeler, inhaler kutularının ağırlığındaki değişiklik, bilgisayar yardımıyla ilaç etkinliği takibi indirekt yöntemler arasında yer almaktadır (Manmohan et al., 2012). Kandaki ilaç, metabolit veya markerların seviyesinin ölçülmesi ise ilaç uyumunu değerlendirmede direkt yöntemler arasında yer almaktadır (Osterberg \& Blaschke, 2005).

Martelli ve arkadaşlarının (2017) İBH hastalarında ilaç uyumunu değerlendirdiği çalışmasında; 5-aminosalisilik asite (5-ASA) uyumsuzluk oranlarının, \%9.5 ila \%65; tiopurine uyumsuzluk oranlarının \%3 ila \%64.7 arasında olduğu belirtilmiştir (Martelli et al., 2017). İnflamatuar Bağırsak Hastalığı olan bireylerde uyumsuzluk nedenleri ve oranlarının incelendiği başka bir çalışmada; 500 İBH hastasının \%33.3'ünün ilaç tedavisine uyum göstermediği, ilaç tedavisine uyum göstermeyenlerin \%42.7'sinin semptomlar geriledikten sonra ilaç tedavisini yarıda kestiği, \%5.2'sinin ise ilacını almayı unuttuğu belirlenmiştir (Ghadir et al., 2016).

Literatürde ülseratif kolitli hastaların mesalazine tedavisine uyumsuz olmalarında; günde dört ya da daha fazla sayıda olacak şekilde reçetelenmesi, erkek cinsiyet, bekar olma, hastalığın iki ya da daha fazla yıldır remisyonda olması, birden fazla (üç yada dört) günlük doz, tablet sayısının fazla olması gibi faktörlerin etkili olduğu belirtilmektedir (Stansfield, 2016). İnflamatuar bağırsak hastalıklarının tıbbi yönetiminde amaç sadece hastalık semptomlarının gerilemesini sağlamak değil 
aynı zamanda hastaların genel iyilik halini arttırıp yaşam kalitesini yükseltmektir (Gracie et al., 2017). Tüm kronik hastalıklarda olduğu gibi İBH'li hastaların ilaç uyumunun düşük olması halinde nüksler, hastalık aktivitesinin artması ve sağlık bakım maliyetlerinin artması söz konusudur (Perry et al., 2018; Gracie et al., 2017).

İnflamatuar bağırsak hastalığına sahip bireylerde ilaç tedavisine uyumun yüksek olmasının hastaların emosyonel, fonksiyonel, sosyal ve fiziksel yaşam kalitesi alt boyutlarını olumlu yönde etkilediği bilinmektedir (Öztürk ve Yıldırım, 2018). Bununla birlikte; hastalığın kronik olması hastalık semptomları gerilediğinde ilaç uyum düzeyinin bu hasta popülasyonunda çeşitli sebeplerle düşmesinin hastaların yaşam kalitesinin özellikle fiziksel, sosyal ve emosyonel alt boyutlarını olumsuz yönde etkilediği düşünülmektedir.

İnflamatuar bağırsak hastalığında, anksiyete, depresyon, somatizasyon ve algılanan stres dahil olmak üzere psikolojik komorbidite sadece aktif hastalık döneminde değil, aynı zamanda inflamasyon yokluğunda devam eden semptomlarla da ilişkilidir (Gracie et al., 2017). Özellikle, akut psikolojik sorunların, ülseratif kolitli bireylerde semptomların alevlenmesine katkıda bulunduğundan sistemik ve mukozal proinflamatuar yanıtları indükleyebileceği belirlenmiştir (İshak et al., 2017). Bu nedenle inflamatuar bağısak hastalığına sahip bireylerin yaşam kalitesinin emosyonel alt boyutunun olumsuz yönde etkilendiği görülmektedir.

Hastalığın kronik olması, hastalık tanısı aldıktan sonraki beden imajındaki değişiklik, semptomların sık tekrarlamas1, ekstraintestinal belirtiler, tıbbi ve cerrahi tedavilerin yan etkileri, kanser gelişme riskinin yarattığı stres ve cerrahiye ihtiyaç duyulması, hastaların günlük yaşam aktivitelerini önemli ölçüde etkileyerek hastaların yaşam kalitesi fiziksel ve sosyal alt boyutunu önemli ölçüde etkilemektedir (Habibi et al., 2017). Lönnfors ve arkadaşlarının (2014) 4670 İBH hastasının yaşam kalitesini araştırdıkları çalışmasında; hastaların \%67'sinin tanı almadan önce en az bir kez acil servise gittiği, \%85'inin tanı aldıktan sonraki 5 yıl içinde en az bir kez hastaneye yatışının olduğu, birçoğunun iş bulmakta güçlük çektiği ve \%45'inin eğitim hayatının kesintiye uğradığ1 belirlenmiştir (Lönnfors, Vermeire \& Avedano 2014). Zargar ve arkadaşlarının (2019) yaptığ1 çalışmada İBH hastalarının \%34.8'inin uyku kalitesinin düşük olduğu belirlenmiştir (Zargar, Gooraji, Keshavarzi \& Aghamohammadi, 2019).

Hastalık aktivitesinin artması intestinal komplikasyonlara, ilaç tedavisinin bir üst aşamaya taşınmasına ve cerrahi tedavi endikasyonuna neden olmaktadır (Perry et al., 2018). İnflamatuar bağırsak hastalığına sahip bireylerde ilaç uyumunun artırılmasıyla; nüksler, hastaneye yatışlar ve komplikasyonların görülme oranı azalacaktır (Yoon, Shin, Park, Park \& Cha, 2017; Hromadkova et al., 2012). Hastalı̆̆ın remisyonda kalması sağlanarak hastaların yaşam kalitesinin yükseleceği düşünülmektedir (Yoon, Shin, Park, Park \& Cha, 2017; Hromadkova et al., 2012; Horvath et al., 2012). 


\section{SONUÇ ve ÖNERILER}

İnflamatuar bağırsak hastalıkları bireylerin özellikle iş, aile, eğitim hayatı gibi önemli yaşam olaylarını kesintiye uğratarak yaşam kalitesini olumsuz yönde etkileyen kronik bir hastalıktır. $\mathrm{Bu}$ doğrultuda sağlı profesyoneli olan hemşirelerin hastanın ilaç uyumsuzluğu işaretlerinin farkında olması (ilaç tedavisine yetersiz yanıt, randevulara vaktinde gelmeme, semptomlar geriledikten sonra ilaç kullanımı bırakma vb.) önemlidir. Buna ek olarak; hastaya ilaç uyumunun yaşam kalitesi üzerine olumlu etkisinin önemine ilişkin hasta eğitimi planlamalıdır. Hemşirelerin özellikle polikliniğe gelen IBH hastalarını yakından takip etmesi ve sürekli iletişim halinde olması, hastanın kullandığı ilaçlara yönelik şikayeti olması durumunda alternatif ilaç tedavisi ile ilgili hekime yönlendirilmesi gereklidir. İnflamatuar bağırsak hastalığına yönelik özel dal hemşireliği geliştirilmesi, akıllı telefon uygulamaları ile hastaların ilaç tedavisine uyumlarının yakından takip edilmesi ile IBH hastalarının ilaç uyumları arttırılabilir. Ayrıca hastaların ilaç uyumunun önündeki engellerin daha iyi anlaşılabilmesi ve yaşam kalitesinin bireyin öznel değerlendirmesine dayalı subjektif bir kavram olduğu düşünüldüğünde konuyla ilgili nitel çalışmaların planlanması önerilmektedir. 


\section{KAYNAKLAR}

Campos, S., Portela, F., Sousa, P., \& Sofia, C. (2016). Inflammatory bowel disease: adherence to immunomodulators in a biological therapy era. European Journal of Gastroenterology \& Hepatology, 28 (11), 1313-1319. doi:10.1097/MEG.0000000000000704.

Davis, S. C., Robinson, B. L., Vess, J., \& Lebel, J. S. (2018). Primary care management of ulcerative colitis. The Nurse Practitioner, 43 (1), 11-19.

Dewulf, N. D. L. S., Monteiro, R. A., Passos, A. D. C., Vieira, E. M., \& Troncon, L. E. D. A. (2007). Compliance to drug therapy in inflammatory bowel diseases outpatients from an university hospital. Arquivos de gastroenterologia,44 (4), 289-296. doi:10.1590/s000428032007000400003.

Fiorino, G., Allocca, M., Chaparro, M., Coenen, S., Fidalgo, C., Younge, L., et al. (2019). 'Quality of care'standards in inflammatory bowel disease: a systematic review. Journal of Crohn's and Colitis, 13 (1), 127-137. doi: 10.1093/ecco-jcc/jjy140.

Ghadir, M. R., Bagheri, M., Vahedi, H., Daryani, N. E., Malekzadeh, R., Hormati, A., et al. (2016). Nonadherence to medication in inflammatory bowel disease: rate and reasons. Middle East Journal of Digestive Diseases, 8 (2), 116. doi: 10.15171/mejdd.2016.16.

Gracie, D. J., Irvine, A. J., Sood, R., Mikocka-Walus, A., Hamlin, P. J., \& Ford, A. C. (2017). Effect of psychological therapy on disease activity, psychological comorbidity, and quality of life in inflammatory bowel disease: a systematic review and meta-analysis. The Lancet Gastroenterology \& Hepatology, 2 (3), 189-199. doi:10.1016/S2468-1253(16)30206-0.

Habibi, F., Habibi, M. E., Gharavinia, A., Mahdavi, S. B., Akbarpour, M. J., Baghaei, A., et al. (2017). Quality of life in inflammatory bowel disease patients: A cross-sectional study. Journal of Research in Medical Sciences: The Official Journal of Isfahan University of Medical Sciences, 22.doi: 10.4103/jrms.JRMS_975_16.

Hromadkova, L., Soukup, T., Cermakova, E., \& Vlcek, J. (2012). Drug compliance in patients with systemic scleroderma. Clinical Rheumatology, 31 (11), 1577-1583. doi: 10.1007/s10067-0122050-0.

Horváth, G., Farkas, K., Hollósi, R., Nagy, F., Szepes, Z., Papp, M., et al. (2012). Is there any association between impaired health-related quality of life and non-adherence to medical therapy in inflammatory bowel disease?. Scandinavian Journal of Gastroenterology, 47 (11), 1298-1303. doi: 10.3109/00365521.2012.703233.

Hwang, J. H., \& Yu, C. S. (2019). Depression and resilience in ulcerative colitis and Crohn's disease patients with ostomy. International Wound Journal, 16, 62-70. doi: 10.1111/iwj.13076. 
Khanna, R., Nelson, S. A., Feagan, B. G., D'Haens, G., Sandborn, W. J., Zou, G. Y., et al. (2016). Endoscopic scoring indices for evaluation of disease activity in Crohn's disease. Cochrane Database of Systematic Reviews, (8). doi: 10.1002/14651858.CD010642.

Kózka, M., Skowron, W., \& Bodys-Cupak, I. (2019). Determinants of the level of anxiety and fears in a group of patients with ulcerative colitis. Annals of Agricultural And Environmental Medicine: AAEM, 26 (2), 337-340. doi: 10.26444/aaem/94651.

Lee, S. H., eun Kwon, J., \& Cho, M. L. (2018). Immunological pathogenesis of inflammatory bowel disease. Intestinal Research, 16 (1), 26. doi: 10.5217/ir.2018.16.1.26.

Lönnfors, S., Vermeire, S., \& Avedano, L. (2014). IBD and health-related quality of life-discovering the true impact. Journal of Crohn's and Colitis, 8 (10), 1281-1286. doi: 10.1016/j.crohns.2014.03.005.

Mahalli, A. A., \& Alharthi, H. M. (2017). Assessment of health-related quality of life of patients with inflammatory bowel diseases in Eastern Province, Saudi Arabia. Journal of Infection and Public Health, 10 (1), 93-101. doi: 10.1016/j.jiph.2016.02.008.

Malinowski, B., Wiciński, M., Sokołowska, M. M., Hill, N. A., \& Szambelan, M. (2020). The rundown of dietary supplements and their effects on Inflammatory Bowel Disease-a review. Nutrients, 12 (5), 1423. doi: 10.3390/nu12051423.

Manmohan, T., Sreenivas, G., Sastry, V. V., Sudha Rani, E., Indira, K., \& Ushasree, T. (2012). Drug compliance and adherence to treatment. Journal of Medical and Dental Sciences, 1, 142-159.

Martelli, L., Lopez, A., Strobel, S., Danese, S., Roblin, X., \& Baumann, C. (2017). Adherence to infliximab therapy in inflammatory bowel disease patients in a real-life setting. Journal of Digestive Diseases, 18 (10), 566-573. doi: 10.1111/1751-2980.12539.

Osterberg, L., \& Blaschke, T. (2005). Adherence to medication. New England Journal of Medicine, 353 (5), 487-497. doi: 10.1056/NEJMra050100.

Park, K. T., Ehrlich, O. G., Allen, J. I., Meadows, P., Szigethy, E. M., Henrichsen, K., et al. (2020). The cost of inflammatory bowel disease: an initiative from the Crohn's \& Colitis Foundation. Inflammatory Bowel Diseases, 26 (1), 1-10. doi: 10.1093/ibd/izz104.

Perry, J., Chen, A., Kariyawasam, V., Collins, G., Choong, C., Teh, W. L. et al. (2018). Medication non-adherence in Inflammatory Bowel Diseases is associated with disability. Intestinal Research, 16 (4), 571. doi: 10.5217/ir.2018.00033.

Pudipeddi, A., Kariyawasam, V., Haifer, C., Baraty, B., Paramsothy, S., \& Leong, R. W. (2019). Safety of drugs used for the treatment of Crohn's disease. Expert Opinion on Drug Safety, 18 (5), 357-367. doi: 10.1080/14740338.2019.1612874. 
Rubin, D. T., Ananthakrishnan, A. N., Siegel, C. A., Sauer, B. G., \& Long, M. D. (2019). ACG clinical guideline: ulcerative colitis in adults. American Journal of Gastroenterology, 114 (3), 384-413. doi: 10.14309/ajg.0000000000000152.

Öztürk, N., Yıldırım, Y. (2018). İnflamatuar Bağırsak Hastalıkları Olan Bireylerde İlaç Uyumu ile Yaşam Kalitesi Arasındaki İlişki. Ege Üniversitesi Sağlık Bilimleri Enstitüsü, Yüksek Lisans Tezi.

Seyedian, S. S., Nokhostin, F., \& Malamir, M. D. (2019). A review of the diagnosis, prevention, and treatment methods of inflammatory bowel disease. Journal of Medicine and Life, 12 (2), 113. doi: 10.25122/jml-2018-0075.

Stansfield, C. (2016). Considerations in the management of ulcerative colitis. Gastrointestinal Nursing, 14 (7), 42-50. doi: 10.12968/gasn.2016.14.7.42.

Trindade, A. J., Ehrlich, A., Kornbluth, A., \& Ullman, T. A. (2010). Are your patients taking their medicine? Validation of a new adherence scale in patients with inflammatory bowel disease and comparison with physician perception of adherence. Inflammatory Bowel Diseases, 17 (2), 599-604. doi: 10.1002/ibd.21310.

Torres, J., Mehandru, S., Colombel, J. F., \& Peyrin-Biroulet, L. (2017). Crohn's disease. The Lancet, 389 (10080), 1741-1755. doi:10.1016/S0140-6736(16)31711-1.

Vlasnik, J. J., Aliotta, S. L., \& DeLor, B. (2005). Medication adherence: factors influencing compliance with prescribed medication plans. The Case Manager, 16 (2), 47-51. doi: 10.1016/j.casemgr.2005.01.009.

Yoon, J. Y., Shin, J. E., Park, S. H., Park, D. I., \& Cha, J. M. (2017). Disability due to inflammatory bowel disease is correlated with drug compliance, disease activity, and quality of life. Gut and Liver, 11 (3), 370. doi:10.5009/gnl16422.

Zargar, A., Gooraji, S. A., Keshavarzi, B., \& Aghamohammadi, A. A. H. (2019). Effect of irritable bowel syndrome on sleep quality and quality of life of inflammatory bowel disease in clinical remission. International Journal of Preventive Medicine, 10. doi:10.4103/ijpvm.IJPVM_364_17. 